\title{
Fabrication of Thorium and Thorium Dioxide
}

\author{
Balakrishna Palanki \\ (Retired) Nuclear Fuel Complex, Hyderabad, India \\ Email: palankibalakrishna@yahoo.com
}

Received 10 November 2014; revised 9 December 2014; accepted 28 December 2014

Copyright (C) 2015 by author and Scientific Research Publishing Inc.

This work is licensed under the Creative Commons Attribution International License (CC BY).

http://creativecommons.org/licenses/by/4.0/

\section{Abstract}

Thorium based nuclear fuel is of immense interest to India by virtue of the abundance of Thorium and relative shortage of Uranium. Thorium metal tubes were being cold drawn using copper as cladding to prevent die seizure. After cold drawing, the copper was removed by dissolution in nitric acid. Thorium does not dissolve being passivated by nitric acid. Initially the copper cladding was carried out by inserting copper tubes inside and outside the thorium metal tube. In an innovative development, the mechanical cladding with copper was replaced by electroplated copper with a remarkable improvement in thorium tube acceptance rates. Oxalate derived thoria powder was found to require lower compaction pressures compared to ammonium diuranate derived urania powders to attain the same green compact density. However, the green pellets of thoria were fragile and chipped during handling. The strength improved after introducing a ball milling step before compaction and maintaining the green density above the specified value. Alternatively, binders were used later for greater handling strength. Magnesia was conventionally being used as dopant to enhance the sinterability of thoria. The normal sintering temperature for magnesia doped thoria was $1600^{\circ} \mathrm{C}-1700^{\circ} \mathrm{C}$, which was achieved in electrically heated molybdenum element sintering furnaces with reducing atmosphere. 0.25 mole percent addition of niobia to the thoria was found to bring down the sintering temperature to $1150^{\circ} \mathrm{C}$. Sintering could be done in ordinary furnaces in air atmosphere using silicon carbide or Kanthal heating elements. Electrical conductivity was measured for both magnesia and niobia doped sintered thoria and used in interpreting differences in sintering behavior.

\section{Keywords}

Thorium, Electroplating, Thorium Dioxide, Pelletizing, Sintering, Coring, Electrical Conductivity 


\section{Introduction}

The work reported in this paper was carried out by this author intermittently during the period 1973 to 2007 . Most of it was documented as internal reports and some of it was published [1]-[10]. Several other valuable publications are also available from literature [11]-[52]. The importance of thorium for the Indian Nuclear Program became clear when it was found that the country was endowed with large mineral resources of thorium. Early development and production work on thorium metal and thorium oxide was carried out at Bhabha Atomic Research Center, Mumbai. Later, thoria pellets for the research reactors CIRUS and DHRUVA, the Fast Breeder Test Reactor (FBTR) as well as the Pressurized Heavy Water Reactor (PHWR) were made at Nuclear Fuel Complex, Hyderabad. The first core of a 220 MWe PHWR requires 385 depleted uranium bundles for flux flattening. It is possible to use thoria bundles instead of depleted uranium oxide bundles. In such a case only 35 thoria bundles are needed [53]. A few export orders were also executed at Hyderabad such as thoria crucibles for emf measurements in Germany and thoria pellets for fusion fission hybrid research facility LOTUS in Switzerland. Some information is presented in the following sections.

\section{Thorium Metal Production}

Thorium oxide powder received from Indian Rare Earths Ltd. was re-calcined at $900^{\circ} \mathrm{C}$. The calcined powder was mixed with calcium granules and reduced at $900^{\circ} \mathrm{C}$ under argon atmosphere. The reacted mass was soaked in water, followed by acid leaching, washing and drying. The powder thus produced was highly pyrophoric and contains impurities carbon, oxygen and nitrogen affecting adversely ductility of the bulk metal. Alternatively, thorium oxalate was chlorinated in the presence of carbon. The crude chloride was purified by vacuum sublimation. The purified chloride was reduced with magnesium to get Th-Mg alloy. The alloy was given a pyro vacuum treatment to separate out the magnesium. The thorium sponge thus obtained was less pyrophoric than the powder. Thorium metal powder was compacted at $300 \mathrm{MPa}$ and sintered in vacuum at $1300^{\circ} \mathrm{C}$ for one hour. $98 \%$ TD could be obtained. The sintered material could be cold rolled to more than $90 \%$ reduction without intermediate annealing [13].

\section{Electroplating Copper on Thorium}

Sintered thorium metal was copper jacketed and hot extruded into tubes. The tubes were then cold drawn to meet surface and dimensional requirements in the specifications. Thorium can not be easily drawn as it galls or seizes the drawing die and hence thorium metal tubes need to be clad before drawing. Copper was chosen as the clad material by virtue of its excellent deformability and compatibility with the die during the cold drawing process. The copper clad thorium tubes were drawn and the copper cladding eliminated by dissolution in nitric acid. Thorium metal itself does not dissolve in nitric acid due to quick passivation. Tubes of ID as small as 9.5 $\mathrm{mm}$ and wall thickness $0.7 \mathrm{~mm}$ were produced. The process of mechanical cladding yielded tubes with wrinkles on the OD which was a cause for rejection. This author had experience in electro less plating and electroplating in the making of Microwave Integrated Circuits which required deposition of copper on alumina substrates [54]. Hence it was decided to try copper deposition on to the thorium tube as an alternative to mechanical cladding. Electro less deposition yields very small thicknesses and used when the cathode is nonconductive. It also requires a number of chemicals for the pre-treatment and plating processes. Electroplating was chosen at the time as a suitable rectifier was readily available.

Copper was deposited in acidic bath using copper sulphate at room temperature. Two anodes were required, a pipe for covering the OD of the thorium tube and a copper rod for ID. The two anodes and the cathode were positioned concentrically maintaining appropriate distances by using a Perspex fixture to hold them in place. Too low a current density yielded coarse copper deposit while a too high a current density yielded a dark deposit. Once these limits are avoided, a large window of current densities is available from plating literature. Separate power supplies were used for the internal anode and external anode to enable independent control of current densities. One would normally expect an increase in plating rate with an increase in current density. But this was not the case with respect to plating on the inner diameter of the thorium tube. The anodic current density for the internal anode was maintained at about half of that of the external anode. This ensured copper deposition of uniform thickness on the inside and outside of the thorium tube. This also prevented passivation of the copper rod and co-deposition of unwanted elements from the bath on to the thorium. The details are shown schemati- 
cally in Figure 1. A similar method was developed later at Hyderabad by this author to deposit copper on zirconium alloy billets before hot extrusion [55].

Thorium is difficult to plate on. It is due to a thin naturally forming oxide surface film that is often difficult to remove and that reforms quickly when a cleaned surface is exposed to air or water. As a result, adherent electrodeposits are obtained only when either: 1 ) the oxide film is removed for sufficient time to permit an initial deposit; 2) the film is replaced with another that does not interfere with adhesion; 3) the film is incorporated into the deposit in a compatible manner; or 4) the surface is severely etched to allow mechanical keying between the substrate and deposit [56]. Successful procedures that rely on one or more of the above principles have been documented. However, for our purpose of cold drawing, maximum adhesion has not been aimed at.

\section{Thorium Dioxide Pelletizing}

Uranium oxide powder was being compacted and sintered on tonnage scale in India since the early seventies. When the requirement of thoria pellets was received, the process parameters of uranium oxide were used for pressing and sintering thorium oxide [15]. However, this led to problems. For example, while a green density of 5.6 to $5.8 \mathrm{~g} / \mathrm{cc}$ worked fine with uranium oxide, the thorium oxide pellets pressed to the same green density yielded pellets that chipped readily on handling. The thorium oxide powder was supplied by India Rare Earths and it was oxalate derived. It was found that the as received powders were not suitable for compacting directly. Therefore a ball milling step was introduced. Ball milled powder yielded green pellets of density over $6.4 \mathrm{~g} / \mathrm{cc}$ and these had better green strength than pellets made from unmilled powders and pressed to $5.8 \mathrm{~g} / \mathrm{cc}$. The pellets on sintering yielded high sintered densities [3] [4].

However it became difficult to control the air radio-activity levels in the milling process in spite of containment. The separation of the balls from the milled powder too posed a problem. Hence the milling process was

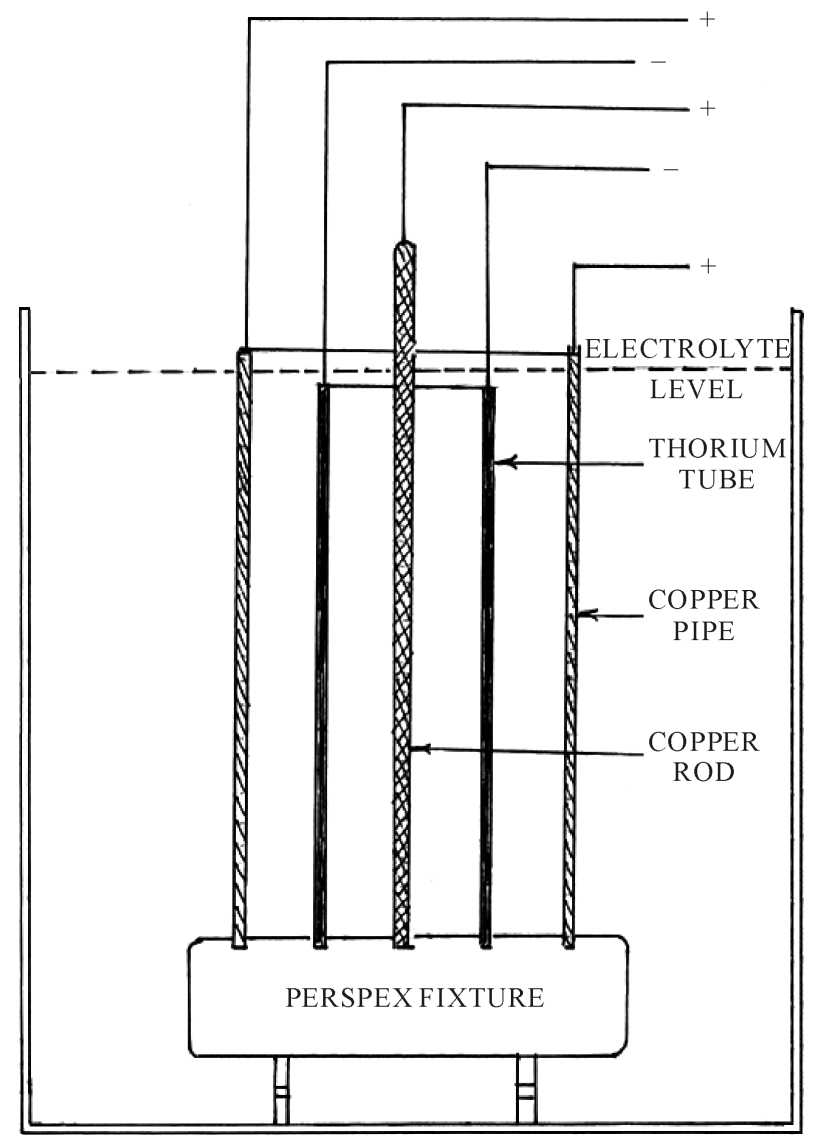

Figure 1. Fixture for holding thorium metal tube, copper rod (internal anode) and copper pipe (external anode). 
discontinued. $1 \%$ by weight Zinc behenate binder was admixed into the thoria powder to yield strong green pellets and finally dense sintered pellets.

\section{Thorium Dioxide Sintering}

\subsection{Additive Effects on Sinterability}

In our early work, it was found that sintering of thoria needed a sintering aid. MgO was being used as sintering aid. $\mathrm{MgSO}_{4}$ was being added to thorium nitrate solution and co-precipitated as oxalate. The oxalate was calcined to yield thorium oxide with about $250 \mathrm{ppm}$ of $\mathrm{Mg}$.

The thoria pellets were sintered in the same furnaces that were being used for sintering $\mathrm{UO}_{2}$ pellets, namely, electrically heated molybdenum element furnaces that operated at $1600^{\circ} \mathrm{C}-1700^{\circ} \mathrm{C}$ in a reducing atmosphere. Later it was found by this author that thorium oxide could be sintered in air at $1150^{\circ} \mathrm{C}$ using 0.25 mole percent $\mathrm{Nb}_{2} \mathrm{O}_{5}$ [3]-[6]. Pellets sintered in a reducing atmosphere ranged in color from bluish gray to white. Those sintered in air ranged from brownish white to white in color. Sintering at $1700^{\circ} \mathrm{C}$ required round the clock shift operation while sintering at $1150^{\circ} \mathrm{C}$ in air could be done in two shifts.

\subsection{Black Spots in Sintered Thoria}

It has been reported that on prolonged heating to $1800^{\circ} \mathrm{C}$ to $1900^{\circ} \mathrm{C}$ in vacuum, thoria blackens with loss of oxygen, although the loss is insufficient to be reflected in chemical analysis or lattice parameter measurements. On reheating in air to $1200^{\circ} \mathrm{C}$ or $1300^{\circ} \mathrm{C}$, the white color is restored [57]. Thoria can also become oxygen deficient due to lower valence cation impurities which leave oxygen sites in the crystal lattice vacant. Black spots were noticed by this author in the thoria pellets sintered in hydrogen at $1700^{\circ} \mathrm{C}$. On analysis it was found to have been caused by iron contamination from the wear out of steel balls in the milling step. This pointed to the need for use of wear resistant balls such as those made of agate or tungsten carbide.

In one of the experiments, a one mm diameter stainless steel wire piece was introduced in a green thoria pellet. On sintering in hydrogen, a $3 \mathrm{~mm}$ diameter black patch resulted. Spectrographic analysis of the black patch revealed the presence of iron, chromium and nickel, the ingredients of stainless steel. The black color is believed to be due to oxygen deficiency in the thoria lattice caused by substitution of Th sites by lower valent $\mathrm{Fe}, \mathrm{Cr}$ or Ni. Niobia added thoria pellets sintered in hydrogen at $1700^{\circ} \mathrm{C}$ were totally black in color. The niobium in reducing atmosphere might have acted as a lower valence additive to thoria.

\subsection{The Phenomenon of Coring}

Thoria pellets could be readily thermal etched to be able to see well defined grain boundaries. A Laser etching technique has been developed for etching thoria for micro structural investigation in reprocessing [24]. Sometimes a cored structure is visible in fractured sintered ceramic pellets. Two types of coring have been mentioned in literature. In one type, reported in thoria and called "picture framing", the grain size in the core was smaller than that in the rim [39]. In another type, reported in alumina, the grain size in the core is much larger than that in the rim [58]. Some of our sintered thoria pellets upon fracturing exhibited a cored structure. The section of the pellet showed a white rim around a glassy inside. In a pellet of $25 \mathrm{~mm}$ diameter, the rim thickness varied from pellet to pellet from $1 \mathrm{~mm}$ to $3 \mathrm{~mm}$. Zawdzki and Apte [59] studied coring in $\mathrm{UO}_{2}$ sintered pellets. They found that a cored structure would result when the heating rate was $400^{\circ} \mathrm{C} / \mathrm{hr}$ and when the $\mathrm{UO}_{2}$ had sulphur impurity of $20 \mathrm{ppm}$ or above. There was no coring when the heating rate was lower, at $250^{\circ} \mathrm{C} / \mathrm{hr}$ for the same material. Coring in Mg doped Alumina was attributed to grain growth inhibition within the cored region. The Mg was thought to have escaped from the rimmed region leading to discontinuous grain growth.

The cored structure appears to be caused by either additives or impurities. Additives are meant for inhibiting grain growth, as $\mathrm{MgO}$ in $\mathrm{Al}_{2} \mathrm{O}_{3}$ and $\mathrm{ThO}_{2}$. The absence of the additive in the rimmed region of the pellet causes discontinuous grain growth leading to the formation of large grains in the rim [58]. Impurities such as Sulphur are capable of causing discontinuous grain growth and their presence in the core region of the pellet causes discontinuous grain growth and large grains in the core [59]. An analysis of the core region of our sintered thoria pellets pointed to the presence of sulphur content above $500 \mathrm{ppm}$. The origin of the sulphur may be in the $\mathrm{MgSO}_{4}$ added to thorium nitrate to provide $\mathrm{Mg}$ as sintering aid. The Sulphur appears to have caused discontinuous grain growth leading to larger grain sizes in the cored region. Recalcination of the thoria powder batches 
that had shown coring on sintering earlier did not show coring again. This author recommends mechanical addition of $\mathrm{MgO}$ to $\mathrm{ThO}_{2}$ powder instead of $\mathrm{MgSO}_{4}$ to $\mathrm{Th}\left(\mathrm{NO}_{3}\right)_{4}$ and co-precipitation.

The green density in a compact in uniaxial or biaxial pressing is usually not uniform unlike in isostatic pressing. The rim is of a higher green density than the inside. At fast rates of heating, and for larger diameter pellets, there is a chance that the surface temperature is higher than the core temperature. The skin with a larger number of particle to particle contacts is likely to densify first leading to subsequent constrained sintering of the core. The situation is further aggravated by the absence of grain growth inhibitors or presence of discontinuous grain growth promoters in certain regions of the pellet.

\subsection{Evaporation and Condensation of Thorium Dioxide}

Two types of sintering furnaces were used for sintering thoria. One type was the pusher type continuous sintering furnace. The other type was a batch sintering furnace. In some sintering runs, the bottom of the water cooled stainless steel lid of the batch sintering furnace was found to have got coated with a while powdery layer, which was identified as thorium oxide. $\mathrm{ThO}_{2}$ seems to have evaporated in the reducing atmosphere from the pellets being sintered and deposited on the underside of the lid.

\section{Electrical Conductivity of Thorium Dioxide with Additives}

Electrical conductivity of sintered thoria was determined by this author at the Plasma Physics Division of BARC [8]. Holes were drilled in the thoria disks prepared for conductivity measurements. Initially, the pellets could not be drilled using even diamond drills. Then it was realized that the drill bits were getting damaged due to quick overheating. The thoria disks fully immersed in water could be readily drilled using drill bits of High Speed Steel. For fixing the contact wires to the sintered thoria disc, platinum paste was used. The electrical conductivity of niobia doped thoria was found to be lower than that of magnesia doped thoria in the temperature range $900^{\circ} \mathrm{C}$ to $1250^{\circ} \mathrm{C}$. From defect chemistry considerations, it can be expected that the effect of addition of higher valence $\mathrm{Nb}_{2} \mathrm{O}_{5}$ to $\mathrm{ThO}_{2}$ would be to enhance the diffusion of thorium in $\mathrm{ThO}_{2}$ and to decrease electrical conductivity. The effect of addition of (lower valence) MgO would be to decrease diffusion and enhance the electrical conductivity. The higher diffusivities of otherwise slowly moving cation mean that a lower sintering temperature would suffice for niobium doped $\mathrm{ThO}_{2}$ than for magnesium doped $\mathrm{ThO}_{2}$. This has indeed been found to be the case, the sintering temperatures being $1150^{\circ} \mathrm{C}$ and $1700^{\circ} \mathrm{C}$, respectively [5].

\section{Dissolution of Thorium Dioxide}

It is generally known that it is very difficult to dissolve sintered thoria rejects for recycling in the pelletizing plant as well as in reprocessing after irradiation. At Hyderabad it was found that $1 \mathrm{~g}$ of sintered thoria readily dissolved in $10 \mathrm{ml}$ of hot concentrated nitric acid with one drop of hydrofluoric acid. In cases where the HF content was larger, the dissolution either slowed down or stopped. It appears that in higher HF concentrations, a coating of $\mathrm{ThF}_{4}$ over the $\mathrm{ThO}_{2}$ might be hindering further dissolution. Niobia doped air sintered thoria required longer time to dissolve compared to hydrogen sintered magnesia doped thoria [9]. Dissolution concerns may have to be addressed while reprocessing after irradiation.

\section{Summary}

Electroplating of copper instead of mechanical cladding resulted in greater acceptance rates of cold drawn thorium metal tubes. The compaction and sintering parameters for thorium oxide were found to be somewhat different from those of uranium oxide. While the conventional additive MgO required a sintering temperature of $1700^{\circ} \mathrm{C}$, achievable in high temperature sintering furnaces with molybdenum elements in a reducing atmosphere, $\mathrm{Nb}_{2} \mathrm{O}_{5}$ brought down the sintering temperature to $1150^{\circ} \mathrm{C}$ which could be achieved in ordinary furnaces with air atmosphere. Electrical conductivity measurements on thoria with $\mathrm{Mg}$ and $\mathrm{Nb}$ additives were made and interpreted with respect to sintering behavior. Coring, that is, the existence of non uniform grain size between the rim of the sintered thoria pellet and the inside is likely when the pellet diameter is large $(25 \mathrm{~mm})$ as in the case of CIRUS research reactor pellets, when the heating rates are rapid $\left(400^{\circ} \mathrm{C} / \mathrm{hr}\right)$ and when there is impurity such as sulphur. Mechanical addition of $\mathrm{MgO}$ to $\mathrm{ThO}_{2}$ powder instead of $\mathrm{MgSO}_{4}$ to $\mathrm{Th}\left(\mathrm{NO}_{3}\right)_{4}$ for co-precipitation is recommended. 


\section{Acknowledgements}

The author is grateful to Mr. R. N. Jayaraj, Chief Executive, Nuclear Fuel Complex for granting permission to publish this paper.

\section{References}

[1] Balakrishna, P., Varma, B.P., Krishnan, T.S., Mohan, T.R.R. and Ramakrishnan, P. (1986) The Role of Point Defects in the Sintering of $\mathrm{UO}_{2}$ and $\mathrm{ThO}_{2}$. Transactions of the Powder Metallurgy Association of India, 13, 117-125.

[2] Balakrishna, P., Varma, B.P., Rajendran, R. and Balaramamoorthy, K. (1987) Thorium Oxide Blanket Fabrication for Indian Fast Breeder Test Reactor. In: Proceedings of TCM, Utilization of Thorium Based Nuclear Fuel: Current Status and Perspectives, 7, 73-88.

[3] Balakrishna, P., Varma, B.P., Krishnan, T.S., Mohan, T.R.R. and Ramakrishnan, P. (1987) Developments in Thoria Calcination, Compaction and Sintering. Transactions of the Powder Metallurgy Association of India, 14, 76-82.

[4] Balakrishna, P., Varma, B.P., Krishnan, T.S., Mohan, T.R.R. and Ramakrishnan, P. (1988) Thorium Oxide: Calcination, Compaction and Sintering. Journal of Nuclear Materials, 160, 88-94. http://dx.doi.org/10.1016/0022-3115(88)90012-8

[5] Balakrishna, P., Varma, B.P., Krishnan, T.S., Mohan, T.R.R. and Ramakrishnan, P. (1988) Low Temperature Sintering of Thoria. Journal of Materials Science Letters, 7, 657-660. http://dx.doi.org/10.1007/BF01730326

[6] Balakrishna, P., Varma, B.P., Rajendran, R., Krishnan, T.S., Balaramamoorthy, K., Mohan, T.R.R. and Ramakrishnan, P. (1989) Activated Sintering of Thoria. Engineering Materials, 29, 669-676.

[7] Balakrishna, P., Somayajulu, G.V.S.R.K., Krishnan, T.S., Mohan, T.R.R. and Ramakrishnan, P. (1991) Developments in Low Temperature Sintering of Thoria. In: Vincenzini, P., Ed., Ceramics Today-Tomorrow's Ceramics, Materials Science Monograph 66D, Elsevier, Amsterdam, 2995-3001.

[8] Balakrishna, P., Ananthapadmanabhan, V. and Ramakrishnan, P. (1994) Electrical Conductivity of Sintered Niobia Doped and Magnesia Doped Thoria. Journal of Materials Science Letters, 13, 86-88. http://dx.doi.org/10.1007/BF00416807

[9] Balakrishna, P. (1994) Characterization and Sintering of Thorium Dioxide. Ph.D. Thesis, Indian Institute of Technology, Bombay.

[10] Balakrishna, P. (2012) $\mathrm{ThO}_{2}$ and (U,Th)O $\mathrm{O}_{2}$ Processing-A Review. Natural Science, 4, 943-949. http://dx.doi.org/10.4236/ns.2012.431123

[11] Kantan, S.K., Raghavan, R.V. and Tendolkar, G.S. (1958) Sintering of Thorium and Thoria. Proceedings of International Conference on Peaceful Uses of Atomic Energy, Geneva, 1-13 September 1958.

[12] Bichakal, S.S., Kini, V.S., Raghavan, R.V. and Garg, R.K. (1974) Preparation of Sinterable Grade Thoria Powder. Proceedings of the Indo-German Seminar on Utilization of Thorium, Bombay, 18-22 November 1974.

[13] Gurumurthy, K.R., Paibhale, S.V., Singh, S.P. and Raghavan, R.V. (1976) Fabrication of Thorium Shapes by Powder Metallurgy. Transactions of Powder Metallurgy Association of India, 3, 47-49.

[14] Rodriguez, P. and Sundaram, C.V. (1981) Nuclear and Materials Aspects of the Thorium Fuel Cycle. Journal of Nuclear Materials, 100, 227-249. http://dx.doi.org/10.1016/0022-3115(81)90534-1

[15] Das, M. and Prasad, P.N. (1984) Thorium Dioxide Pellets for Reactor Fuel Elements. Specification PP-M-784.

[16] Chandramouli, V., Anthonysamy, S., Vasudeva Rao, P.R., Divakar, R. and Sudararaman, R. (1996) PVA Aided Microwave Synthesis: A Novel Route for the Production of Nanocrystalline Thoria Powder. Journal of Nuclear Materials, 231, 213-220. http://dx.doi.org/10.1016/0022-3115(96)00368-6

[17] Joseph, K., Sridharan, R. and Gnanasekaran, T. (2000) Kinetics of Thermal Decomposition of Th $\left(\mathrm{C}_{2} \mathrm{O}_{4}\right)_{2} \cdot 6 \mathrm{H}_{2} \mathrm{O}$. Journal of Nuclear Materials, 281, 129-139. http://dx.doi.org/10.1016/S0022-3115(00)00241-5

[18] Purohit, R.D., Saha, S. and Tyagi, A.K. (2001) Nanocrystalline Thoria Powders via Glycine-Nitrate Combination. Journal of Nuclear Materials, 288, 7-10. http://dx.doi.org/10.1016/S0022-3115(00)00717-0

[19] Ananthasivan, K., Anthonysamy, S., Sudha, C., Terrance, A.L.E. and Vasudeva Rao, P.R. (2002) Thoria Doped with Cations of Group VB-Synthesis and Sintering. Journal of Nuclear Materials, 300, 217-229. http://dx.doi.org/10.1016/S0022-3115(01)00736-X

[20] Ananthasivan, K., Anthonysamy, S., Singh, A. and Vasudeva Rao, P.R. (2002) De-Agglomeration of Thorium Oxalate-A Method for the Synthesis of Sinter Active Thoria. Journal of Nuclear Materials, 306, 1-9. http://dx.doi.org/10.1016/S0022-3115(02)01229-1

[21] Balakrishnan, K., Majumdar, S., Ramanujam, A. and Kakodkar, A. (2002) The Indian Perspective on Thorium Fuel 
Cycles. Thorium Fuel Cycle: Options and Trends, IAEA TECDOC-1319, 257-265.

[22] Dash, S., Singh, A., Ajikumar, P.K., Subramaniam, H., Rajalakshmi, M., Tyagi, A.K., Arora, A.K., Narasimhan, S.V. and Raj, B. (2002) Synthesis and Characterization of Nano Crystalline Thoria Obtained from Thermally Decomposed Thorium Carbonate. Journal of Nuclear Materials, 303, 156-168. http://dx.doi.org/10.1016/S0022-3115(02)00816-4

[23] Kutty, T.R.G., Khan, K.B., Hegde, P.V., Banerjee, J., Sengupta, A.K., Majumdar, S. and Kamath, H.S. (2004) Development of a Master Sintering Curve for $\mathrm{ThO}_{2}$. Journal of Nuclear Materials, 327, 211-219. http://dx.doi.org/10.1016/j.jnucmat.2004.02.007

[24] Sinha, S., Ramadasan, E., Jatha, V.P., Dasgupta, K., Sahoo, K.C. and Gantayet, L.M. (2007) Laser Etching of Thoria Pellets for Microstructural Investigations. Applied Science, 253, 4404-4408.

[25] Anantharaman, K., Shivakumar, V. and Saha, D. (2008) Utilization of Thorium in Reactors. Journal of Nuclear Materials, 383, 119-121. http://dx.doi.org/10.1016/j.jnucmat.2008.08.042

[26] Banerjee, J., Kutty, T.R.G., Kumar, A., Kamath, H.S. and Banerjee S. (2011) Densification Behavior and Sintering Kinetics of $\mathrm{ThO}_{2}-4 \% \mathrm{UO}_{2}$ Pellet. Journal of Nuclear Materials, 408, 224-230. http://dx.doi.org/10.1016/j.jnucmat.2010.11.029

[27] Banerjee, S. and Govindan Kutty, T.R. (2012) Functional Materials. Nuclear Fuels, 10, 387-466.

[28] Saller, H.A. and Keeler, J.R. (1953) The Fabrication of Thorium Tubes. BMI-805, Batelle Memorial Institute.

[29] Johnson, J.R. and Curtis, C.E. (1954) Properties of Thorium Oxide Ceramics. Interim Report ORNL 1809.

[30] Johnson, J.R. and Curtis, C.E. (1954) Note on Sintering of Thoria. Journal of the American Ceramic Society, 37, 611. http://dx.doi.org/10.1111/j.1151-2916.1954.tb13996.x

[31] Beach, J.G. and Schaer, G.R. (1959) Electroplating on Thorium. Journal of the Electrochemical Society, 106, $392-393$. http://dx.doi.org/10.1149/1.2427366

[32] Harada, Y., Baskin, Y. and Handwerk, J.H. (1962) Calcination and Sintering Study of Thoria. American Ceramic Society, 45, 253-257. http://dx.doi.org/10.1111/j.1151-2916.1962.tb11139.x

[33] (1966) Utilization of Thorium in Power Reactors. Technical Reports Series No. 52, IAEA, Vienna.

[34] Matzke, H.J. (1967) Xenon Migration and Trapping in Doped ThO$_{2}$. Journal of Nuclear Materials, 21, 190-198. http://dx.doi.org/10.1016/0022-3115(67)90149-3

[35] Pope, J.M. and Radford, K.C. (1974) Physical Properties of Some Thoria Powders and Their Influence on Sinterability. Journal of Nuclear Materials, 52, 241-254. http://dx.doi.org/10.1016/0022-3115(74)90171-8

[36] Weinreich, A.W., Britton, W.H., Hutchison, C.R., Johnson, R.G.R. and Burke, T.J. (1977) Fabrication of High Density, High Integrity Thorium Based Fuel Pellets. Transactions of the American Nuclear Society, 27, 305-307.

[37] (1979) Status and Prospects of Thermal Breeders and Their Effect on Fuel Utilization, Technical Reports Series No. 195, IAEA, Vienna.

[38] White, G.D., Bray, L.A. and Hart, P.E. (1981) Optimization of Thorium Oxalate Precipitation Conditions Relative to Derived Oxide Sinterability. Journal of Nuclear Materials, 96, 305-313. http://dx.doi.org/10.1016/0022-3115(81)90574-2

[39] Belle, J. and Berman, R.M. (1981) Thorium Dioxide-Properties and Nuclear Applications. DOE/NE-0060. http://dx.doi.org/10.2172/5986642

[40] (1987) Utilization of Thorium-Based Nuclear Fuel: Current Status and Perspectives. Proceedings of TCM, IAEATECDOC-412, IAEA, Vienna.

[41] Tetsuo Shiratori, K. and Fukuda, K. (1993) Fabrication of Very High Density Fuel Pellets of Thorium Dioxide. Journal of Nuclear Materials, 202, 98-103. http://dx.doi.org/10.1016/0022-3115(93)90033-U

[42] Altas, Y., Eral, M. and Tel, H. (1997) Preparation of Homogeneous $\left(\mathrm{Th}_{0.8} \mathrm{U}_{0.2}\right) \mathrm{O}_{2}$ Pellets via Coprecipitation of (Th,U) $\left(\mathrm{C}_{2} \mathrm{O}_{4}\right)_{2} \cdot \mathrm{nH}_{2} \mathrm{O}$ Powders. Journal of Nuclear Materials, 249, 46-51. http://dx.doi.org/10.1016/S0022-3115(97)00185-2

[43] (2000) IAEA-TECDOC-1155. IAEA, Vienna.

[44] (2002) IAEA-TECDOC-1319. IAEA, Vienna.

[45] MacDonald, P.E. (2002) Advanced Proliferation Resistant, Lower Cost, Uranium-Thorium Dioxide Fuels for Light Water Reactors, Idaho National Engineering and Environmental Laboratory INEEL/EXT-02-01411.

[46] IAEA (2005) Thorium Fuel Cycle-Potential Benefits and Challenges. IAEA, Vienna.

[47] Grosse, K.-H., Hrovat, M. and Seemann, R. (2009) Manufacturing Technology for Thorium Based Fuel Elements. Proceedings of Conference on Characterization and Quality Control of Nuclear Fuels, Hyderabad, 18-20 February 2009. 
[48] Hingant, N., Clavier, N., Dacheux, N., Barre, N., Hubert, S., Obbade, S., Taborda, F. and Abraham, F. (2009) Preparation, Sintering and Leaching of Optimized Uranium Thorium Dioxides. Journal of Nuclear Materials, 385, 400-406. http://dx.doi.org/10.1016/j.jnucmat.2008.12.011

[49] Hingant, N., Clavier, N., Dacheux, N., Hubert, S., Barré, N., Podor, R. and Aranda, L. (2011) Preparation of Morphology Controlled $\mathrm{Th}_{(1-x)} \mathrm{U}_{x} \mathrm{O}_{2}$ Sintered Pellets from Low Temperature Precursors. Powder Technology, 208, 454-460. http://dx.doi.org/10.1016/j.powtec.2010.08.042

[50] (2012) Role of Thorium to Supplement Fuel Cycles of Future Nuclear Energy Systems. STI/PUB/1540, IAEA, Vienna.

[51] Csom, Gy., Reiss, T., Fehér, S. and Czifrus, Sz. (2012) Thorium. Annals of Nuclear Energy, 41, 67-78.

[52] Das, D. and Bharadwaj, S.R. (2013) Thoria Based Nuclear Fuels: Thermophysical and Thermodynamic Properties, Fabrication, Reprocessing and Waste Management. Google eBook: Business \& Economics Springer Science \& Business Media.

[53] Balakrishnan, M.R. (1992) India Prepares for Its First Load of Thorium Fuel. Nuclear Engineering International, 37, 14.

[54] Balakrishna, P. and Mahapatra, S. (1973) Electroless Copper on Alumina and Other Substrates. Plating, 60, 636-639.

[55] Balakrishna, P., Murty, B.N., Jha, S.K., Krishnan, P.K. and Saibaba, N. (2005) Electroplating of Copper on Annular Zirconium Alloy Billets. Plating and Surface Finishing, 92, 56-61.

[56] Dini, J.W. and Johnson, H.R. (1980) Plating on Some Difficult to Plate Metals and Alloys. SAND 79-8069, Sandia Laboratories.

[57] Peterson, S., Adams, R.E. and Douglas Jr., D.A. (1965) Properties of Thorium, Its Alloys and Its Compounds. ORNLTM-1144. http://web.ornl.gov/info/reports/1965/3445601336962.pdf

[58] Burke, J.E., Lay, K.W. and Prochazka, S. (1980) The Effect of MgO on the Mobility of Grain Boundaries and Pores in Aluminum Oxide. In: Kuczynski, G.C., Ed., Sintering Processes, Plenum Press, London.

[59] Zawidzki, T.W., Apte, P.S. and Hoare, M.R. (1984) Effect of Sulphur on Grain Growth in $\mathrm{UO}_{2}$ Pellets. Journal of the American Ceramic Society, 67, 361-364. http://dx.doi.org/10.1111/j.1151-2916.1984.tb19537.x 
Scientific Research Publishing (SCIRP) is one of the largest Open Access journal publishers. It is currently publishing more than 200 open access, online, peer-reviewed journals covering a wide range of academic disciplines. SCIRP serves the worldwide academic communities and contributes to the progress and application of science with its publication.

Other selected journals from SCIRP are listed as below. Submit your manuscript to us via either submit@scirp.org or Online Submission Portal.
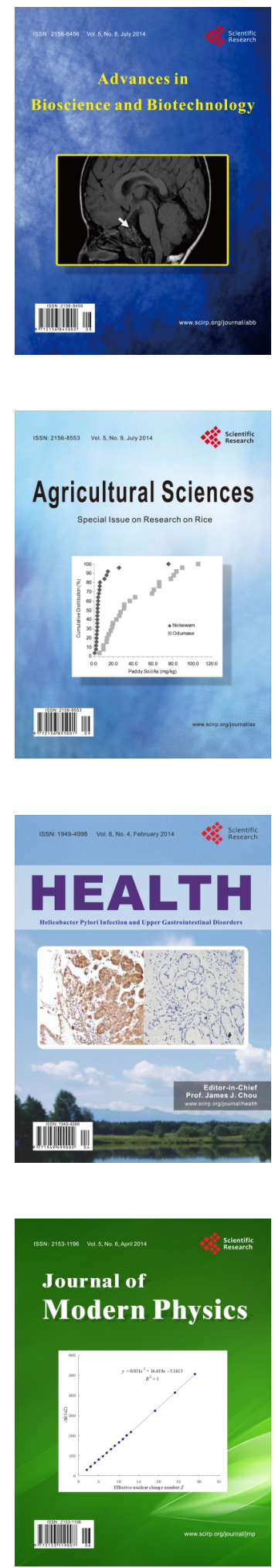
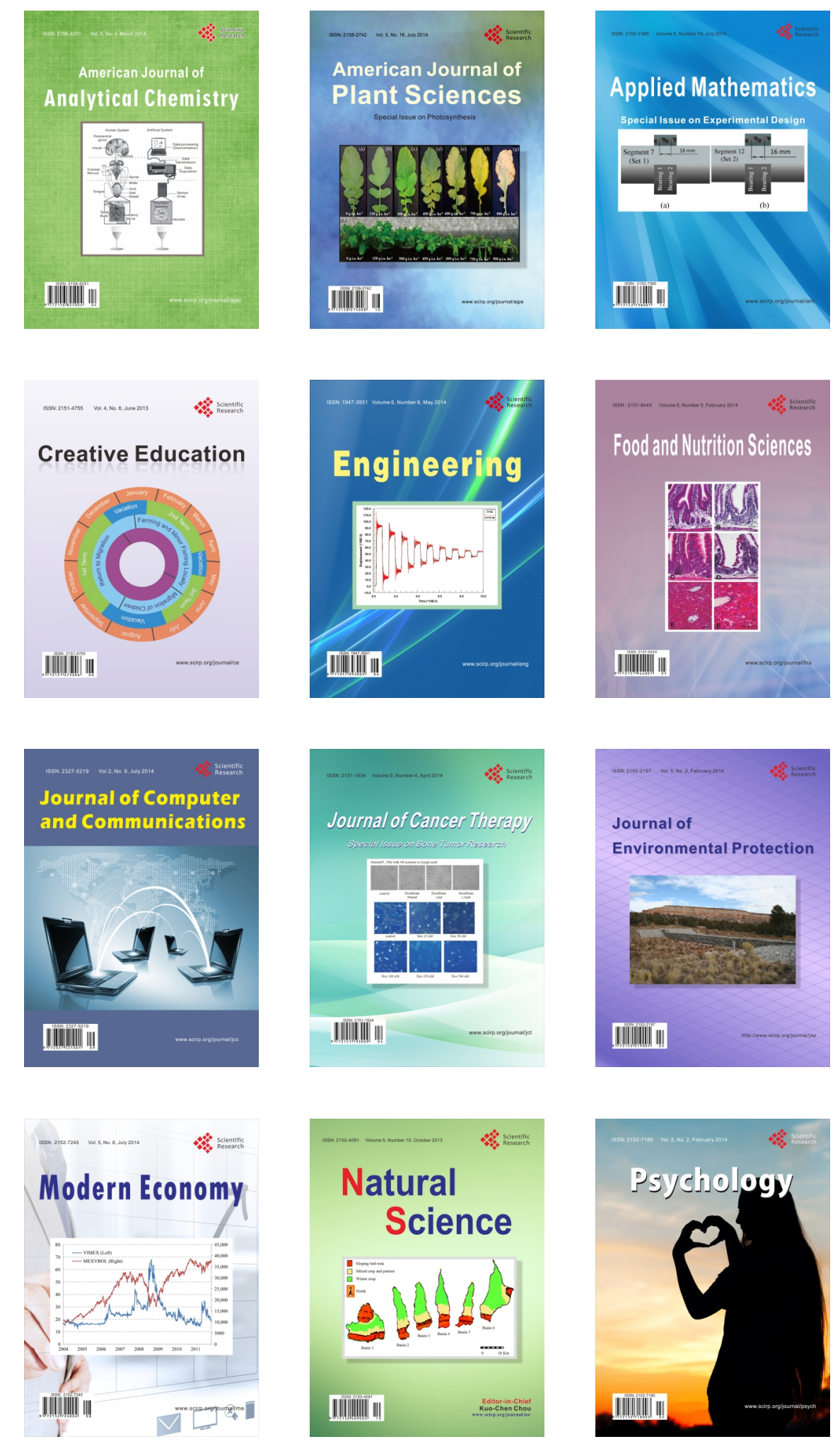